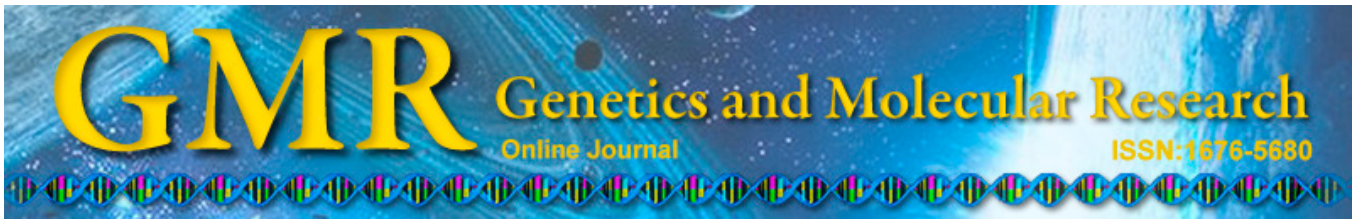

\title{
Role of IL-6 polymorphism on the development of cardiovascular events and coronary artery disease in patients receiving hemodialysis
}

\author{
Y. Song, H.D. Gu, Y. He and J.W. Wang \\ Department of Nephrology, People's Hospital of Rizhao, Shandong, China \\ Corresponding author: S. Yan \\ E-mail: songyan667@yeah.net
}

Genet. Mol. Res. 14 (1): 2631-2637 (2015)

Received April 22, 2014

Accepted October 20, 2014

Published March 30, 2015

DOI http://dx.doi.org/10.4238/2015.March.30.23

\begin{abstract}
We aimed to investigate the role of IL-6 polymorphism on the development of cardiovascular events and coronary artery disease in patients receiving hemodialysis. Blood samples were collected from 216 patients receiving hemodialysis treatment. Polymerase chain reaction-restriction fragment length polymorphism (PCR-RFLP) was used to genotype IL-6 -634C/G, -174G/C and $-572 \mathrm{C} / \mathrm{G}$. By multivariate analysis, we found that the IL-6 -634GG genotype was associated with increased risk of cardiovascular events in patients receiving hemodialysis, with $\mathrm{HR}(95 \% \mathrm{CI})$ of 4.07 (1.20-15.70). Similarly, we found that the IL-6-174CC genotype was related to the onset and development of cardiovascular events in patients receiving hemodialysis, with $\mathrm{HR}(95 \% \mathrm{CI})$ of 3.33 (1.219.51). However, we did not find an association between IL-6 -572C/G polymorphism and risk of cardiovascular events in patients receiving hemodialysis. Our study suggests that IL-6 -634C/G and $-174 \mathrm{G} / \mathrm{C}$ polymorphisms are associated with risk of cardiovascular events in patients receiving hemodialysis.
\end{abstract}

Key words: IL-6; Polymorphism; Hemodialysis; Cardiovascular events 


\section{INTRODUCTION}

Atherosclerotic cardiovascular diseases (CVD) are the main reasons for the death of patients receiving hemodialysis (Fujisawa et al., 2000). Local vascular inflammation related to venous neointimal hyperplasia is considered a predictive marker for fistula stenosis. Moreover, previous studies have reported that inflammation is associated with cardiovascular mortality in patients on dialysis (Yeun et al., 2000; Kaysen, 2001). Most patients with end-stage renal disease present with chronic inflammation (Yao et al., 2004; Stenvinkel et al., 2005). Multiple factors have a role in inflammation in end-stage renal disease, including genetic factors (Stenvinkel et al., 2005).

Interleukin-6 (IL-6) is a proinflammatory and immunoregulatory cytokine found in diverse tissues, including fibroblasts, monocytes, adipocytes, and endothelial cells. IL-6 has a role in the genesis and maintenance of the inflammatory response (Satti et al., 2013). The polymorphism of the IL- 6 gene is associated with different levels of secreted protein according to the genotype. There are several polymorphisms in IL-6, including $-634 \mathrm{C} / \mathrm{G},-174 \mathrm{G} / \mathrm{C}, 572 \mathrm{G} / \mathrm{C}$ and $-597 \mathrm{G} / \mathrm{A}$ (Rao et al., 2005). Three functional proteins in the IL-6 gene, $-634 \mathrm{C} / \mathrm{G},-174 \mathrm{G} / \mathrm{C}$, and $-572 \mathrm{C} / \mathrm{G}$, are widely investigated for their association with risk of various diseases (Mandić et al., 2013; Sung et al., 2014; Yang et al., 2014; Nie et al., 2014). These two gene polymorphisms may influence CVD susceptibility by altering gene regulation and protein expression (Morgan et al., 2006). Several studies have shown that IL-6 gene polymorphisms are associated with risk of cardiovascular events in patients receiving hemodialysis (Marrone et al., 2007; Liu et al., 2008; Aker et al., 2009). Moreover, IL-6 polymorphism is regarded as an aggravating factor in the development and progression of renal disease (Kitamura et al., 2002; Aker et al., 2009).

In our study, we aimed to investigate the role of IL-6 polymorphism in the development of cardiovascular events and coronary artery disease in patients receiving hemodialysis.

\section{MATERIAL AND METHODS}

\section{Study population}

The study included 216 patients receiving hemodialysis treatment for $12-15 \mathrm{~h}$ per week in People's Hospital of Rizhao. Data were collected between January 2009 and December 2010. All patients were angiographically diagnosed with CAD. CAD was diagnosed as the presence of one or more stenoses of $>50 \%$ in at least one major artery or a main stem stenosis of $>30 \%$.

Informed consent was obtained from patients or their relatives before enrolling them in this study. Each case and control was asked to provide $5 \mathrm{~mL}$ blood for DNA sequencing.

The medical history of all patients was collected when enrolling them in study. The lipids and inflammation parameter and genotyping were conducted at the time of coronary angiography, and patients were followed up after coronary angiography. Coronary interventions and death were defined as the endpoints of the study, including percutaneous coronary angioplasty with or without stenting, and coronary artery bypass grafting (CABG) as well as myocardial infarction (MI). Patients were censored when they received renal transplantation. The study protocol was approved by the ethics committee of the People's Hospital of Rizhao.

All patients were followed up until December 30, 2013, with a median follow-up time of 35.2 months (range of 2 to 60 months). All patients were followed up by telephone every four weeks until coronary interventions, death, or the end of study. 


\section{Genotyping analysis}

Venous blood was collected in ethylenediamine tetraacetic acid (EDTA)-coated tubes and stored at $-20^{\circ} \mathrm{C}$ until use. Genomic DNA was extracted using the TIANamp blood DNA kit (Tiangen Biotech, Beijing, China) according to manufacturer instructions. Polymerase chain reaction- restriction fragment length polymorphism (PCR-RFLP) was used to genotype IL-6 $-634 \mathrm{C} / \mathrm{G},-174 \mathrm{G} / \mathrm{C}$ and $-572 \mathrm{C} / \mathrm{G}$. Primers and probes of IL-6 $-634 \mathrm{C} / \mathrm{G},-174 \mathrm{G} / \mathrm{C}$ and $-572 \mathrm{C} / \mathrm{G}$ were designed using the Sequenom Assay Design 3.1 software. PCR was performed in a $30-\mu \mathrm{L}$ reaction solution containing $25 \mathrm{mM} \mathrm{MgCl}_{2}, 2 \mathrm{mM} 4 \mathrm{X}$ dNTP, $20 \mu \mathrm{M}$ primer and 5 $\mathrm{U} / \mu \mathrm{L}$ Taq DNA polymerase. PCR was started at $94^{\circ} \mathrm{C}$ for $5 \mathrm{~min}$, followed by denaturation at $94^{\circ} \mathrm{C}$ for $45 \mathrm{~s}$, annealing at $62^{\circ} \mathrm{C}$ for $60 \mathrm{~s}$ and extension at $72^{\circ} \mathrm{C}$ for $60 \mathrm{~s}$, and a last extension at $72^{\circ} \mathrm{C}$ for $10 \mathrm{~min}$. Reproducibility was verified by repeat analysis of a randomly chosen subgroup of $10 \%$ of the subjects.

\section{Statistical analysis}

Continuous variables are reported as means \pm standard deviation (SD), while categorical variables are expressed as frequencies and percentages (\%). Homozygotes of the most frequent genotype were regarded as the reference group. The Cox proportional hazards models were used to evaluate the effect of IL-6 $-634 \mathrm{C} / \mathrm{G},-174 \mathrm{G} / \mathrm{C}$ and $-572 \mathrm{C} / \mathrm{G}$ polymorphisms on progressionfree survival (PFS) and cardiovascular events and coronary artery disease in patients receiving hemodialysis, and the results are reported as hazard ratio (HR) and 95\% CI. The Kaplan-Meier method was used to plot survival curves. All $\mathrm{P}$ values were two-tailed, and differences were considered to be statistically significant when $\mathrm{P}<0.05$. The $\mathrm{SPSS}^{\circledR}$ statistical package, version 11.0 (SPSS Inc., Chicago, IL, USA) for Windows ${ }^{\circledR}$ was used for statistical analyses.

\section{RESULTS}

\section{Characteristics of study population}

The demographic and clinical characteristics of the study population are shown in Table 1. The mean age of included subjects was $58.6 \pm 10.6$ years. Of the 216 patients, 132 (61.11\%) were males, and $155(71.76 \%)$ had hypertension. The duration of hemodialysis was $5.7 \pm 3.2$ years. The levels of creatinine, albumin, total cholesterol, LDL-C, hemoglobin and platelets were $66.8 \pm 21.5 \mathrm{mg} / \mathrm{dL}, 9.13 \pm 2.3 \mathrm{mg} / \mathrm{dL}, 3.53 \pm 0.24 \mathrm{mg} / \mathrm{dL}, 157.3 \pm 28.3 \mathrm{mg} / \mathrm{dL}$, $103.5 \pm 31.6 \mathrm{mg} / \mathrm{dL}, 9.5 \pm 0.5 \mathrm{~g} / \mathrm{dL}$ and $204.6 \pm 62.5 \times 10^{3} / \mu \mathrm{L}$.

During the follow-up period, a total of 88 patients $(40.74 \%)$ had CAD, coronary revascularization and cardiovascular events as well as death.

The distributions of IL-6 genotypes are shown in Table 2. By multivariate analysis, we found that the IL-6 -634GG genotype was associated with increased risk of cardiovascular events in patients receiving hemodialysis, with HR (95\%CI) of 4.07 (1.20-15.70) (Figure 1). Similarly, we found that the IL-6-174CC genotype was related to the onset and development of cardiovascular events in patients receiving hemodialysis, with HR $(95 \% \mathrm{CI})$ of 3.33(1.219.51) (Figure 2). However, we did not find an association between IL-6 -572C/G polymorphism and risk of cardiovascular events in patients on hemodialysis. 
Table 1. Characteristics of subjects included.

\begin{tabular}{lc}
\hline Indexes & Patients $(\%)$ \\
\hline Age, years & $58.6 \pm 10.6$ \\
Gender & $132(61.11)$ \\
$\quad$ Male & $84(38.89)$ \\
$\quad$ Female & $61(28.24)$ \\
Hypertension & $155(71.76)$ \\
$\quad$ No & $5.7 \pm 3.2$ \\
$\quad$ Yes & $66.8 \pm 21.5$ \\
Duration of hemodialysis, years & $9.13 \pm 2.3$ \\
Blood urea nitrogen $($ BUN), mg/dL & $3.53 \pm 0.24$ \\
Creatinine, mg/dL & $157.3 \pm 28.3$ \\
Albumin, g/dL & $103.5 \pm 31.6$ \\
Total cholesterol, mg/dL & $9.5 \pm 0.5$ \\
LDL-C, mg/dL & $204.6 \pm 62.5$ \\
Hemoglobin, g/dL & \\
Platelet, $x 10^{3} / \mu L$ &
\end{tabular}

Table 2. Correlation between IL-6 -634C/G, $-174 \mathrm{G} / \mathrm{C}$, and $-572 \mathrm{C} / \mathrm{G}$ polymorphisms and CAD, coronary revascularization and cardiovascular events in patients receiving hemodialysis.

\begin{tabular}{|c|c|c|c|c|c|c|}
\hline IL-6 gene polymorphism & Patients & $\%$ & Events & $\%$ & $\mathrm{HR}(95 \% \mathrm{CI})^{1}$ & $P$ value \\
\hline \multicolumn{7}{|l|}{$-634 \mathrm{C} / \mathrm{G}$} \\
\hline $\mathrm{CC}$ & 131 & 60.6 & 46 & 52.3 & 1.0 (Ref.) & - \\
\hline CG & 69 & 32.1 & 31 & 35.5 & $1.51(0.80-2.85)$ & 0.18 \\
\hline GG & 16 & 7.3 & 11 & 12.2 & $4.07(1.20-15.70)$ & 0.009 \\
\hline \multicolumn{7}{|l|}{$-174 \mathrm{G} / \mathrm{C}$} \\
\hline GG & 102 & 47.2 & 34 & 39.4 & 1.0 (Ref.) & - \\
\hline GC & 90 & 41.6 & 38 & 43.5 & $1.46(0.78-2.74)$ & 0.2 \\
\hline $\mathrm{CC}$ & 24 & 11.2 & 15 & 17.1 & $3.33(1.21-9.51)$ & 0.008 \\
\hline \multicolumn{7}{|l|}{$-572 \mathrm{C} / \mathrm{G}$} \\
\hline $\mathrm{CC}$ & 122 & 56.4 & 46 & 53.3 & 1.0 (Ref.) & - \\
\hline $\mathrm{CG}$ & 51 & 23.4 & 23 & 25.9 & $1.36(0.66-2.77)$ & 0.37 \\
\hline GG & 44 & 20.2 & 18 & 20.8 & $1.14(0.53-2.44)$ & 0.71 \\
\hline
\end{tabular}

${ }^{1}$ Adjusted for gender, age, hypertension, duration of hemodialysis, BUN, creatinine, albumin, total cholesterol, LDL-C, hemoglobin and platelet.

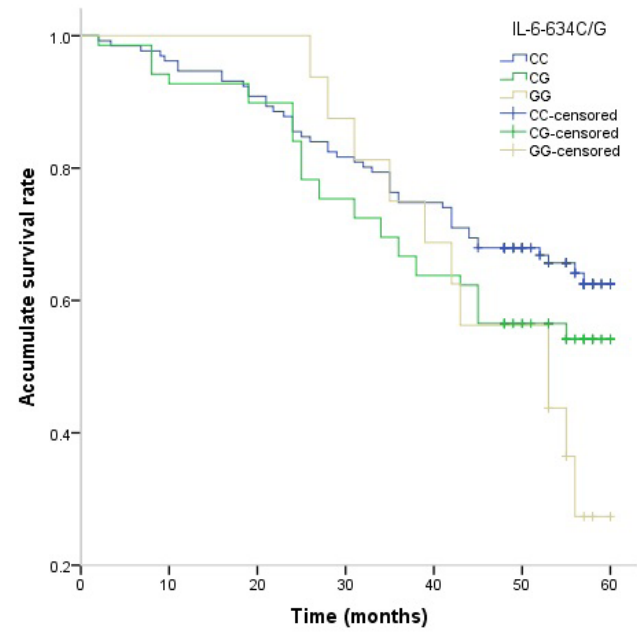

Figure 1. Kaplan-Meier analysis of association between IL-6 -634C/G polymorphism and cardiovascular events in patients receiving hemodialysis. 


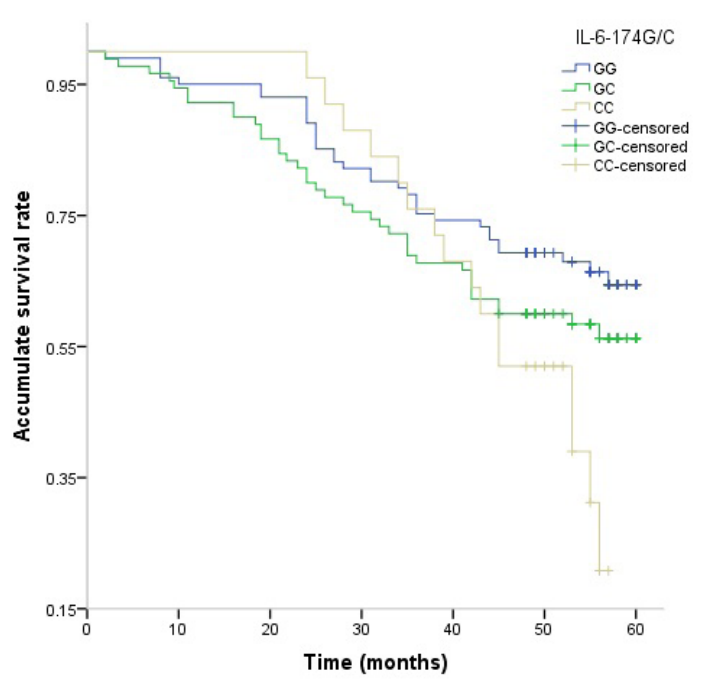

Figure 2. Kaplan-Meier analysis of association between IL-6 -174G/C polymorphism and cardiovascular events in patients receiving hemodialysis.

\section{DISCUSSION}

Interleukin-6 is one of the most common effectors in the inflammatory cascade (Rao et al., 2005). Il-6 is a circulating multifunctional cytokine secreted in response to different types of inflammatory insults. It is reported that increased circulating levels of IL-6 are associated with various diseases in patients with end-stage renal disease, including malnutrition, hypertension, left ventricular hypertrophy, atherosclerosis and cardiovascular events (Brull et al., 2001; Losito et al., 2003; Rao et al., 2005). IL-6 can cause endothelial cell damage, stimulate intracellular adhesion molecule and increase the attachment and diapedesis of leukocytes across endothelial cells (Pigott et al., 1992). Several previous studies have indicated that elevated levels of IL-6 can stimulate vascular smooth muscle cell growth, and thus increase endothelial synthesis of plasminogen activator inhibitor, and finally result in progressive fistula stenosis in end-stage renal disease patients on hemodialysis. In our study, we found that the IL-6 -634GG and IL-6-174CC genotypes were associated with increased risk of cardiovascular events in patients receiving hemodialysis.

Previous studies have shown that IL-6 -634GG or G allele is a risk factor for renal disease progression (Kitamura et al., 2002; Buraczynska et al., 2007; Ryu and Kim, 2012). Kitamura et al. (2002) conducted a study in Japan, and reported that IL-6 -634C/G polymorphism may be a possible genetic susceptibility factor for the progression of diabetic nephropathy. Buraczynska et al. (2007) conducted a study in Poland to investigate whether the SNPs in the promoter region of the IL-6 gene was associated with the development of chronic glomerulonephritis, and reported that the IL-6 $-634 \mathrm{C} / \mathrm{G}$ polymorphism may be a possible risk factor for faster progression of chronic glomerulonephritis to end-stage renal disease (Buraczynska et al., 2007). Ryu and Kim (2012) conducted a study in Korea and found that the IL-6-634 G allele was associated with greater frequency in patients with end-stage renal disease and could be associated with patients with end-stage renal disease. We found that the IL-6 -634GG geno- 
type was associated with increased risk of cardiovascular events in patients on hemodialysis, which is in agreement with previous studies (Kitamura et al., 2002; Buraczynska et al., 2007; Ryu and Kim, 2012). Therefore, IL-6-634C/G appears to be associated with progression of patients with end-stage renal disease.

In our study, we also found that the IL-6-174CC genotype was associated with increased risk of cardiovascular events in patients receiving hemodialysis. However, previous studies did not find an association between IL-6-174G/C polymorphism and progression of patients with end-stage renal disease (Kitamura et al., 2002; Buraczynska et al., 2007; Ryu and Kim, 2012). The discrepancy in the results may be explained by the differences in ethnicities, sample size and also by chance. Further studies are greatly needed to confirm the association between IL-6$174 \mathrm{G} / \mathrm{C}$ polymorphism and risk of cardiovascular events in patients on hemodialysis.

In conclusion, this study is the first to report that IL-6 -634GG and IL-6-174CC genotypes are associated with increased risk of cardiovascular events in end-stage renal disease patients receiving hemodialysis. Further large-sample studies are warranted to confirm our results.

\section{REFERENCES}

Aker S, Bantis C, Reis P, Kuhr N, et al. (2009). Influence of interleukin-6 G-174C gene polymorphism on coronary artery disease, cardiovascular complications and mortality in dialysis patients. Nephrol. Dial. Transplant. 24:2847-2851.

Brull DJ, Montgomery HE, Sanders J, Dhamrait S, et al. (2001). Interleukin-6 gene $-174 \mathrm{G}>\mathrm{C}$ and $-572 \mathrm{G}>\mathrm{C}$ promoter polymorphisms are strong predictors of plasma interleukin-6 levels after coronary artery bypass surgery. Arterioscler Thromb. Vasc. Biol. 21:1458-1463.

Buraczynska M, Jozwiak L, Ksiazek P, Borowicz E, et al. (2007). Interleukin-6 gene polymorphism and faster progression to end-stage renal failure in chronic glomerulonephritis. Transl. Res. 150:101-105.

Fujisawa M, Haramaki R, Miyazaki H, Imaizumi T, et al. (2000). Role of lipoprotein (a) and TGF- $\beta 1$ in atherosclerosis of hemodialysis patients. J. Am. Soc. Nephrol. 11:1889-95.

Kaysen GA (2001). The microinflammatory state in uremia: causes and potential consequences. J. Am. Soc. Nephrol. 12:1549- 1557.

Kitamura A, Hasegawa G, Obayashi H, Kamiuchi K, et al. (2002). Interleukin-6 polymorphism (-634 C/G) in the promotor region and the progression of diabetic nephropathy in type 2 diabetes. Diabet. Med. 19:1000-1005.

Liu BC, Li L, Gao M, Wang YL et al. (2008). Microinflammation is involved in the dysfunction of arteriovenous fistula in patients with maintenance hemodialysis. Chin. Med.J. 121:2157-2161.

Losito A, Kalidas K, Santoni S and Jeffery S (2003). Association of interleukin-6 -174G/C promoter polymorphism with hypertension and left ventricular hypertrophy in dialysis patients. Kidney Int. 64:616-622.

Mandić S, Sudarević B, Marczi S, Horvat V, et al. (2013). Interleukin-6 polymorphism and prostate cancer risk in population of Eastern Croatia. Coll. Antropol. 37:907-11.

Marrone D, Pertosa G, Simone S, Loverre A, et al. (2007). Local activation of interleukin 6 signaling is associated with arteriovenous fistula stenosis in hemodialysis patients. Am. J. Kidney Dis. 49:664-673.

Morgan L, Cooper J, Montgomery H, Kitchen N, et al. (2006). The interleukin-6 gene $-174 \mathrm{G}>\mathrm{C}$ and $-572 \mathrm{G}>\mathrm{C}$ promoter polymorphisms are related to cerebral aneurysms. J. Neurol. Neurosurg. Psychiatry 77:915-917.

Nie W, Xue L, Sun G, Ning Y, et al. (2014). Interleukin-6 -634C/G polymorphism is associated with lung cancer risk: a meta-analysis. Tumour Biol. [Epub ahead of print]

Pigott R, Dillon LP, Hemingway IH and Gearing AJ (1992). Soluble forms of E-selectin, ICAM-1 and VCAM-1 are present in the supernatants of cytokine activated cultured endothelial cells. Biochem. Biophys. Res. Commun. 187:584-589.

Rao M, Guo D, Perianayagam MC, Tighiouart H, et al. (2005). Plasma interleukin-6 predicts cardiovascular mortality in hemodialysis patients. Am. J. Kidney Dis. 45:324-333.

Ryu JH and Kim SJ (2012). Interleukin-6 $-634 \mathrm{C} / \mathrm{G}$ and $-174 \mathrm{G} / \mathrm{C}$ polymorphisms in Korean patients undergoing hemodialysis. Korean J. Intern. Med. 27:327-37.

Satti HS, Hussain S and Javed Q (2013). Association of interleukin-6 gene promoter polymorphism with coronary artery disease in Pakistani families. Scientific World J. 538365.

Stenvinkel P, Pecoits-Filho R, Lindholm B and DialGene Consortium (2005). Gene polymorphism association studies in dialysis: the nutrition-inflammation axis. Semin Dial. 18:322-330. 
Sung JW, Lee SH, Byrne CD, Chung PW, et al. (2014). High-sensitivity C-reactive protein is associated with the presence of coronary artery calcium in subjects with normal blood pressure but not in subjects with hypertension. Arch. Med. Res. 45:170-176.

Yang X, Feng L, Li C and Li Y (2014). Association of IL-6-174G $>$ C and $-572 C>$ G polymorphisms with risk of young ischemic stroke patients. Gene: S0378-1119.

Yao Q, Lindholm B and Stenvinkel P (2004). Inflammation as a cause of malnutrition, atherosclerotic cardiovascular disease, and poor outcome in hemodialysis patients. Hemodial. Int. 8:118-129.

Yeun JY, Levine RA, Mantadilok V and Kaysen GA (2000). C-Reactive protein predicts all-cause and cardiovascular mortality in hemodialysis patients. Am. J. Kidney Dis. 35:469-476. 